\title{
The Theoretical Framework of Teacher Collaboration
}

\author{
Lyailya Shakenova \\ Queen's University Belfast, UK
}

\section{Introduction}

Lortie (1975) drew attention to the problem of isolation and school improvement in his work.He defined a school as cellular structured classrooms, which means that classrooms are isolated from each other and do not allow teachers to interact with each other in the school.According to Lortie (1975) isolation prevents improving creativity and teaching instructions. When it comes to the possible solutions to teacher isolation, Saunders, Goldenberg, \&Gallimore (2009) and Kelchtermans, 2006 suggested teacher collaboration as a way to stop teacher isolation. Saunders. Nevertheless, approaches to teacher collaboration are not generally agreed, but various: while some researchers such as Hargreaves (1994) state the positive effects of collaboration, others including Jonson (2003) focus on negative impact of collaboration on teachers, school culture and effectiveness. So, this study examine the broad literature on collaboration with a deep analyses of collaborative culture with special focus on forms and characteristics and the factors promoting and restricting collaboration. The study is a result of deep and comprehensive analyse of literature: 334 articles and 52 books.

Collaborative culture as a supporting element of collaboration is particularly analysed through the forms (isolation; collaboration; contrived collegiality; balkanization; a 'moving mosaic)and characteristics (being spontaneously organized by teachers themselves and may be supported by management sector; being voluntary based without managerial tension; being development-oriented; taking place any time and any space;having unpredictable outcomes) suggested by Hargreaves (1994).

Factors affecting teacher collaboration are explored and analysed in two categories: factors restricting teacher collaboration and factors promoting teacher collaboration. As many as possible opinions and approaches are explored and analysed to come to a conclusion on both factors restricting teacher collaboration and factors promoting teacher collaboration and be able to summarise these factors. 


\section{The importance of collaboration}

Some studies (Woodlanda, Lee\&Randalla, 2013; Meirink, Meijer \&Verloop, 2007) have pointed out that teacher learning can be positively improved through collaboration with colleagues, through sharing ideas, experience, and resources, through giving feedback in order to become reflective about the teaching practice, and through supporting each other. Moreover, according to the study of Goddard, Goddard, \&Tschannen-Moran (2007) there is a link between teacher collaboration and students' achievements.In other words as the teachers are improving teaching skills and knowledge, they start to influence classroom instructions.Dufour, Dufour, \&Eaker (2005, p. 232-233) stated the importance of collaboration in providing high quality education:

The purpose of school is to see to it that all of our students learn at high levels, and the future of our students depends on our success. We must work collaboratively to achieve that purpose, because it is impossible to accomplish if we work in isolation.

When it comes to definitions of teacher collaboration, Kelchtermans (2006) defined collaboration as teachers' cooperation aimed at achieving the school objectives. Hord (1986) explained the difference between collaboration and cooperation.He claimed that cooperation is considered as an action where two or more teachers consent to improve their individual practice through working together.While collaboration means sharing obligations and involving teachers in decision making about shared teaching practice.Kruse (1999) claimed that notions of collaboration, cooperation and collegiality are different concepts, but they are interrelated.According to Kruse (1999), cooperation between teachers happens when they provide basic assistance to their colleagues without sharing common values. Whereas collegiality is described as joint learning and discussion about teaching practice and students' achievements. Therefore according to Kruse (1999) collaboration is defined as shared values, decision making about teaching practice and interaction between teachers, which promotes students' performance and the professional development of staff.

Thus, collaboration means shared values through teachers' learning which influences teaching practice and students' achievements.Moreover, shared decision making about common goals and practice plays a pivotal role in school improvement, and is based on cooperation between teachers and collegial relationships. 


\section{Collaborative culture}

As mentioned above, teacher collaboration has a positive impact on school effectiveness, so it has become a governing principle of educational reforms (Hargreaves, 1994).One of the main factors that affect the teacher collaboration and interaction between teachers can be determined as school culture. According to Deal and Kennedy (1982, p.14), culture has a great impact on what is happening in the organisation, 'the way we do things around here'.Fullan\& Hargreaves (1992) identified a collaborative culture as an organizational environment where staff exchange ideas; it is one of the main activities of teachers' daily work.

\subsection{Forms of collaborative culture}

Some of the main features of collaborative culture were suggested by Nias, Southworth and Yeomans (1989) in their book 'Staff relationships in the primary school'.According to Niaset al. (1989), collaborative culture does not mean working together on one task or official organizational meetings.Collaborative culture appears in everyday activities, organizational events and ceremonies, during the exchange of ideas and experience and analysing of teaching practice. They argue that teachers, while working together, demonstrate trust, openness, support and help in everyday activities and these can be considered as the basic features of collaborative culture.Moreover, in relation to other features of collaboration, Niaset al. (1989) pointed out the importance of valuing individuals and groups at the same time.Rosenholtz (1989) outlined two types of school culture.The first is 'moving' schools, where learning is one of the main features and teachers support each other and talk.The second type of culture is 'stuck' schools, in which teacher isolation and estrangement are the norm.

However, Hargreaves (1994) suggested five forms of collaborative teacher culture that are different from one another and have their own particular characteristics. They are: isolation, collaboration, contrived collegiality, balkanization and a 'moving mosaic'.In his work Hargreaves (1994) examined collaborative cultures through the prism of relationship between teachers and their colleagues.In addition, he outlined the benefits and drawbacks of each form of teacher culture.

Hargreaves (1994) stated isolation has been criticized by some researchers as negative practice.However, in some cases it may also have positive effects. For example, some teachers create and plan better alone than in groups.Therefore, he suggested three types of individualism: 1) constrained individualism happens when teachers work individually because of some structural conditions; 2) strategic individualism means the situations where teachers intentionally take position of 
working alone; and 3) elective individualism means the choice to work collaboratively or alone depending on the current situation (p. 172).

Furthermore, Hargreaves (1994) identified the characteristics of collaborative culture as: 1) being spontaneously organized by teachers themselves and may be supported by management sector; 2) being voluntary based without managerial tension; 3) being development-oriented; 4) taking place any time and any space; 5) having unpredictable outcomes.

The third form of collaborative culture is contrived collegiality, which is in direct contrast to the collaborative culture mentioned above. In contrived collegiality, collaboration among school staff is administratively regulated, compulsory, implementation-orientated, fixed in time and place, and the outcomes are predictable.However, Hargreaves (1992) argued that contrived collegiality is equivocal.It can influence teacher collaboration positively and negatively depending on the situations in which it is used.

The fourth form of collaborative teacher culture is balkanization, which is associated with independent groups of teachers and the presence of competition between these groups within a school.Hargreaves (1994, p 215) stated that in a culture of balkanization some groups succeed and other groups lose, 'In balkanized cultures, there are winners and losers'. He outlined the following characteristics of balkanized teacher culture: 1) low permeability which means the existence of subgroups separated from each other with apparent boundaries; 2) personal identification to a particular subject department or stage; 3) high permanence of sub-groups; 4) political complexion which refers to the possession of power that influences the distribution of resources and promotion.

The last form of teacher culture according to Hargreaves (1994, p 239) is a 'moving mosaic'.Moving mosaic is associated with flexibility, creativity, risktaking and continuous professional development among school staff.In a moving mosaic culture there are loose departmental boundaries and teachers can belong to more than one sub-group; teachers can learn from their colleagues in other subject departments.The heads of departments are voted in by teachers for a short period. Moreover, the warm, respectful relationships among teachers in moving mosaic culture promote open discussion and solution of problems. 


\section{Benefits and drawbacks of collaboration}

Opinions on the benefits of collaboration are diverse and sometimes opposing. Regarding the benefits of collaboration, Hargreaves (1994) claimed that collaboration has apositive influence on some aspects, such as increasing teacher efficacy, professional development and learning opportunities, responsibility for work, reflection on instructional practice and reducing work overload.

However, at the same time Hargreaves (1994, p.247) claimed that collaboration has negative aspects in its realizations: '...collaboration carries with it great danger also, in ways that can be wasteful, harmful and unproductive for teachers and their students'.He claims that collaboration can be: 1) conformist, which can lead to the groupthink that forbids working in solitude and ensures all ideas come from it; 2) contrived, where collaboration is controlled by administration, so teachers work without desire and inefficiently; 3) co-optative, where teachers have to achieve the goals set by others; 4) comfortable and complacent, where teachers usually work together, share resources and provide moral support; working practice is very flexible, and not properly organized.

A more recent study confirms the disadvantages of teacher collaboration.Jonson (2003) identified the drawbacks of teacher collaboration: work intensification, loss of autonomy, interpersonal conflicts and factionalism.

Nevertheless, the positive effects of collaboration on teacher learning and moral support are outlined by Johnson (2003).He identified that teachers emotionally and psychologically find that working together with colleagues is beneficial, because collaboration gives them a chance to learn from each other.Moreover, collaborative experiences provide more opportunities for teachers to make networks of relationships which can help them to share their reflective experience, evaluate beliefs on teaching and learning and construct knowledge together (Achinstein, 2002; Chan \& Pang, 2006; Clement \&Vandenberghe, 2000).So, collaborative activities are described as being a main element of professional development.It is possible to say that collaboration is a type of social interaction and this social interaction plays an important role in producing knowledge (John-Steiner, 2000). Therefore, providing the opportunity to produce knowledge can be considered one of the advantages of collaboration.

The role of collaboration in school reform was studied by Gable and Manning (1997). They state that collaboration supports an environment that is docile to new aspects, opportunities and attitudes. When it comes to the benefit of collaboration for teacher development, John-Steiner (2000) identifies collaboration as a central element of professional development. 
Thus, according to the literature, collaboration between teachers has more benefits than drawbacks.The benefits of teacher collaboration can be determined as professional growth, morale and material support, reduction of work overload, increase in teacher reflection and effectiveness, and reduction in teacher absenteeism.

\section{Factors restricting teacher collaboration}

As Hargreaves (1994) noted, teacher collaboration is time consuming as well as difficult in sustaining a collaborative culture at school. There are some factors that restrict the promotion of teacher collaboration such as time, culture and micropolitics.

\subsection{Time}

In the literature on the subject of school reform time was determined to be one of the strongest barriers to innovation and educational change: 'Time compounds the problem of innovation and confounds the implementation of change' (Hargreaves, 1994, p. 95).Collinson and Cook (2013) identified five barriers to teacher collaboration that are related to the lack of time: not enough discretionary time to share, feeling overwhelmed, not enough discretionary time to learn, lack of common time with colleagues, and lack of a designated time to share.In Collinson and Cook's (2013, p.92) case study, teachers stressed that they do not have enough common free time to share and learn during the teaching day, so learning and sharing activities usually take place during holidays:

During the summer, I had to sit down and relax and be calm and work and work and work on it [integrating the technology into instructions], and that really, really motivated me. Then I had the chance to talk with other project people in the building. You know, we shared and shared (Michael).

In addition, Fullan and Hargreaves (1992, p.9) pointed out the problem of overload.They claim that as a result of educational reforms teachers have more responsibilities mostly related to social and behavioural problems:

Teachers and heads are dangerously overloaded.More social work responsibilities, greater accountability and having to deal with a wider range of abilities and behaviours in their classroom are now all part of the teacher's lot. 


\subsection{Micropolitics}

"Micropolitics refers to the use of formal and informal power by individuals and groups to achieve their goals in organization" (Blase, 1991, p11).

According to Hargreaves (1994), teachers and administration represent different politics and views within a school.Teachers are obliged to fulfil undesirable managerial tasks, so this situation can cause collaboration to turn into co-optation. Moreover, Hargreaves (1994) noted that micro political perspectives can be noticed in collaborative culture that is administratively controlled to stimulate collegiality; this situation is close to contrived collegiality.

\subsection{Culture}

Hargreaves and Fullan (1992) predicted that three types of collaborative culture should be avoided.They are: 1) contrived collegiality - collaboration is administratively controlled and not voluntary, which can diminish teachers' motivation to collaborate; 2) balkanized culture - in this type of culture separate and competing groups exist with their own goals and views which can lead to the conflict between groups and individuals due to lack of communication and interaction between teachers; 3) comfortable culture can be associated with the notion of cooperation (Kruse,1999), where teachers usually work with each other for a short period without shared values.

In other words, time and work overload can be considered as the main factors that restrict opportunities to learn and share. Moreover, they are interdependent of one other, because culture and micropolitics are interrelated.

\section{Factors promoting teacher collaboration}

There are many different factors that play an important role in supporting teacher collaboration.Silva andMorgado (2005) identified several factors which influence teacher collaboration.They are: 1) personal and professional factors include openness to different opinions, volunteering, a sense of responsibility, motivation and relationships with colleagues; 2)the team social atmosphere is supported by respect, common goals, the ability to listen to each other and talk; 3) organisational factors include teachers' schedules, deployment of resources, distribution of tasks and support from management staff.However, Kelchtermans (1996) divided these factors into two main areas: structural conditions and interpersonal dynamics.Structural conditions refer to the factors existing in a school and district, and interpersonal dynamics refer to teachers' behaviours and attitudes. In terms of 
this research Kelchtermans' classification of structural conditions and interpersonal dynamics will be used to identify the factors which promote collaboration in NIS.

\subsection{Structural conditions}

One of the structural conditions supporting teacher collaboration is whether to have common goals (Cohen and Ball, 1999).As Friend and Cook (2000) claimed, goals which were decided jointly by all teachers can guarantee the effectiveness of their teamwork through clear understanding of objectives by all participants.West (1990) found in his research that teams that defined their goals together are more positive towards innovations and more willing to participate in development of these innovations.In addition, Cohen and Ball (1999) addressed the importance of setting common goals not only inside schools, but also among different schools to achieve collaboration. Therefore, establishing mutual goals is vital for team members to achieve a good outcome (Johnson \& Johnson, 2000).

Another structural condition is whether to have formal time to meet (Little, 1990). Generally, if teachers have common time and goals at the same time, this can provide the opportunity for sharing that will inevitably increase collaboration among them (Collinson \& Cook, 2001).In contrast, the pressure on teachers in relation to scheduling time can have a negative influence on collaboration Hargreaves (1994).In situations where the time for collaboration is administratively controlled, there can be an impact on teachers' motivation and can also create contrived collegiality (Hargreaves, 1994).According to Collinson and Cook (2001), the most rewarding form of scheduling time is the combination of arbitrary time for teachers to learn on their own and teacher-directed time organized for learning together and sharing.Another form of formal meeting can be a grade-level meeting, characterised by Strahan (2003), which has its own aim of improving teaching practice.All forms of meetings are crucial in as much as they are linked to classroom practice (Bronstein, 2013).

However, not only having formal time to meet, but also having informal time to meet is considered a structural condition promoting teacher collaboration (Goddard et al., 2007; Strahan, 2003). According to Little (1990), regular meetings where teachers can discuss teaching and learning and plan lessons together are more effective than formal meetings that occur once a month.

Another structural condition is being able to share with a colleague who has more experience, which also plays an important role in the development of knowledge (Berk and Hiebert, 2009).According to Rust (2009), getting feedback from experienced people is particularly important in developing skills.According to (Bronstein, 2013), the experienced colleague can be a mentor, formal or informal. 
The main task of a mentor is to support novice teachers and help them with the curriculum, improving instructional skills and classroom management (Roberts \& Pruitt, 2003).

According to Louis and Kruse (1995), to ensure effective collaboration teachers should be located in close proximity to one other, so they can observe colleagues' lessons and discuss teaching and learning easily.Therefore, having access to the physical space to meet with colleagues also promotes the collaboration within a school (Stoll, Bolam, McMahon, Wallace \& Thomas, 2006).McGregor (2003) identified some spaces where teachers usually meet: classrooms, department offices and staffrooms.However, Stoll et al., (2006) state that it is much better to have a place where teachers can have refreshments and discuss different professional issues in the same building 'a school structure where it is easier to have coffee and professional discussions in a subject workroom rather than go to the staffroom located in another building, is likely to inhibit school-wide collegiality' (p. 234).

Furthermore, having an opportunity to observe your colleagues' lessons or to be observed by them is another structural condition that supports teacher collaboration.According to Roberts and Pruitt (2003, p119), through observations teachers usually learn from each other and establish common assumptions.So, as a result teachers promote collaborative culture which positively influences on teaching and learning:

Classroom teachers should observe one another to foster a culture in which they collaborate, learn from another, and construct shared pedagogical beliefs and strengths. The outcome is the building of community and a culture of collaborative instruction that fosters improved teaching and learning.

Therefore, in this subsection the structural conditions which promote collaboration were identified such as physical space, observations, formal and informal time and common goals.In the next subsection the interpersonal dynamics will be discussed.

\subsection{Interpersonal dynamics}

One of the interpersonal dynamics is dialogue and active participation. Hansen, Hill, McWalters, Paliokas\&Stumbo (2010) claimed that teachers can actively take part in decision-making. 'Dialogue, then, is not simply talking - it is professional learning and it is sometimes deep professional learning' (Southworth, 2009).Furthermore, an effective dialogue is considered a factor contributing to collaboration by giving teachers an opportunity to create desirable connections among them.Colleagues' attempts to talk clearly, completely and concretely about 
their work help to take the enigma out of teaching (Little, 1990). Kruse, Louis $\&$ Bryke (1995) also emphasised the importance of communication among teachers, as far as the teachers share experience, learn from each other though interaction.

Another factor influencing teacher collaboration is trust. ${ }^{\circ}$ Trust in people remains important, but trust in expertise and processes supersedes it', (Fullan\& Hargreaves, 1992, p. 98).Needless to say open communication is a main element of collaboration and an important condition to ensure clear communication in an organisation is trust (O'Reilly \& Roberts, 1977).Particularly when it comes to collaboration, trust and collaboration are mutual operations; they depend on each other and feed one another (Tschannen-Moran, 2001).Baier (1986) emphasised that trust is inevitable in co-operating and communicating effectively to establish efficient relationships in a group. Moreover, as Tschannen - Moran (2001) stated, if teachers do not trust they will be worried about their self-determination and not collaborate with their colleagues.

Positive attitudes towards teaching can be considered as another interpersonal dynamics. First of all, teachers have a great impact on their students, they can inspire the students and support effective atmosphere in the classrooms, in other words, with their positive attitudes teachers influence favourably on their students and the relationship between students and them (Pianta, 1999; Watson, 2003). Moreover teachers' attitudes towards teaching play an irreplaceable role in collaboration and these attitudes must be positive (Smith, Wilson, \& Corbett, 2009).

Another interpersonal dynamics is having shared beliefs and understandings. According to most theorists, shared understandings and vision are the main elements in building partnerships (Westheimer, 1999). According to Schlechty (2005) the willingness to collaborate with peers depends on the shared beliefs or visions, which are explicit for all teachers and they desire to realize them.Moreover, communities where people are ready to work cooperatively have advantages in forming learning communities (Smith, Wilson \& Corbett, 2009).

Openness and respect are another interpersonal dynamics which support teacher collaboration. Communication based on openness raises the possibility of learning and developing (Smylie, 1994). According to Kruse et al. (1995) the sharing of teaching practice through interaction can lead to the openness, so teachers can observe the lessons of their colleagues. Another point of view to the openness was discussed by Bauwens\&Hourcade (1995). They claimed that teachers should be open to new innovations and changes in education to meet students' new requirements. 'The openness....creates connections and breaks down barriers' 
(Deal and Peterson, 2009,p186). Silva and Morgado (2005) stated that one of the important elements to achieve collaboration is respect. They claimed that teachers should accept opinions which are diverse from their own and respect their input into the process. Moreover this idea was brought forward by Niaset al. (1989) in their book 'Staff relationships in the primary school'. The researchers stated that teachers should be valued as individuals.

And the final interpersonal dynamics is teachers' initiatives. To succeed by interacting with colleagues teachers take responsibility and risks that develop teaching and student learning (CCSSO, 2011).'Once risk taking gets rolling, we learn more from our new experience' (Fullan and Hargreaves, 1992, p97). In their guidance for teachers they supported initiatives and gave some advice how to do the first step towards collaboration.Danielson (2011) created the criteria where the distinguished teacher is a person who takes initiative : "take a leadership role in promoting a culture of professional inquiry" (p. 48). Therefore according to this interpersonal dynamics Bronstein (2013) distinguished active and passive teachers in his work.

\section{Conclusion}

In this study the theoretical framework of teacher collaboration was outlined. Teacher collaboration is identified by certain researchers as joint work with shared values by (Horb, 1986; Kruse, 1999).Collaboration has a positive influence on teacher learning through sharing experience, ideas and, in its turn, teacher learning affects students' performance through enrichment of subject knowledge and instructional skills.In addition, teacher collaboration reduces teachers' overload by sharing material and provides moral support for their colleagues. However, collaboration reduces teachers' autonomy in teaching practice and can diminish teachers' motivation in cases where collaborative activities are controlled by administrative staff.Moreover, the collaborative cultures such as collaboration, isolation, balkanized culture, moving mosaic, comfortable collaboration and contrived collegiality were discussed in this chapter in order to understand school cultures which are favourable for maintaining teacher collaboration.Time, school culture and micropolitics were identified as barriers to teacher collaboration, while having formal and informal time to meet with colleagues, having common goals with colleagues, having an opportunity to observe colleagues or to be observed by them, having access to a physical space, as well as shared understanding, trust, dialogue-active participation, respect, teachers' initiatives and positive attitudes towards teaching were identified as factors supporting teacher collaboration. 


\section{References and notes:}

Achinstein, B. (2002) 'Conflict amid community: the micropolitics of teacher collaboration', Teachers College Record, 104(3), pp421-455.

Baier, A. (1986) 'Trust and Antitrust', Ethics, 96(2), pp. 231-260.

Bauwens, J. \&Hourcade, J.J. (1995) Cooperative Teaching: Rebuilding the Schoolhouse for all Students. Austin, TX: PRO-ED.

Berk, D., \&Hiebert, J. (2009) 'Improving the mathematics preparation of elementary teachers, one lesson at a time', Teachers and Teaching: Theory and Practice, 15(3), pp337-356.

Blase, J. (1991) The Politics of Life In Schools: Power, Conflict and Cooperation. London: Sage Publications.

Bronstein, A.S. (2013) 'Teacher collaboration in the age of teaching standards: the study of a small, suburban school district'a dissertation in Educational and Organizational Leadership Presented to the Faculties of the University of Pennsylvania in Partial Fulfillment of the Requirements for the Degree of Doctor of Education.

Brownell, M.T., Yeager, E., Rennells, M.S., \& Riley, T. (1997) 'Teachers working together: What teacher educators and researchers should know. Teacher Education and Special Education', The Journal of the Teacher Education Division of the Council for Exceptional Children, 20(4), 340-359.

Bush, T. (2011) Theories of educational leadership and management, $4^{\text {th }}$ edn., London; Los Angeles: Sage.

Chan, C.K., \& Pang, M.F. (2006) 'Teacher collaboration in learning communities', Teaching Education, 17(1), pp1-5.

Clement, M., \&Vandenberghe, R. (2000) ' Teachers' professional development: A solitary or collegial (ad)venture?', Teaching and Teacher Education, 16(1), pp81-101.

Cohen, D. K., \& Ball, D. L. (1999). Instruction, capacity, and improvement. CPRE Research Report no.RR-043).Philadelphia: University of Pennsylvania, Consortium for Policy Research in Education. Available at: http://files.eric.ed.gov/fulltext/ED431749.pdf(Last accessed 6 June 2016).

Collinson, V. \& Cook, T. F. (2001) 'I don't have enough time: Teachers'interpretations of time as a key to learning and school change', Journal of Educational Administration, 39(3), pp266-281.

Cook, T.F. \&Collinson, V. (2013) 'Influences on Teacher Sharing and Collaboration' in Conley, S. \& Cooper, B.S. (Eds) Moving from Teacher Isolation to Collaboration. Plymouth: Rowman \& Littlefield Education, pp.81-99.

Council of Chief State School Officers. (2011). InTASC model core teaching standards. Washington, D.C.

Danielson, C. (2011) The Framework for Teaching Rubric: 2011 Revised Edition. San Francisco, CA: Teachscape. Available at:http://usny.nysed.gov/rttt/teachersleaders/practicerubrics/Docs/Teachscape_Rubric.pdf(Last accessed 30 July 2014).

Southworth, G (2009) 'Learning-centred leadership', in Davies, B. The Essentials of School Leadership. Los Angeles: Sage, pp91-111.

Deal, T., \& Kennedy, A. (1982) Corporate Cultures. Reading, MA: Addison-Wesley.

Deal, T. E. \& Peterson, K. D. (2009, $2^{\text {nd }}$ Edition) Shaping School Culture. San Fransisco: Jossey-Bass.

DuFour, R., Eaker, R., \& DuFour, R. (2005) On Common Ground: The Power of Professional Learning Communities. Bloomington, IN: Solution Tree. 
Dunn, T.G., \& Shriner, C. (1999) 'Deliberate practice in teaching: What teachers do for self improvement', Teaching and Teacher Education, 15(6), 631-651.

Friend, M. \& Cook, L. (2000, $3^{\text {rd }}$ Edition) Interactions - Collaboration Skills for School Professionals. New York: Longman.

Fullan, M.\& Hargreaves, A. (1992) What's Worth Fighting for in your School: Working Together for Improvement. Buckingham: Open University Press in association with the Ontario Public School Teachers' Federation.

Gable, R.A., \& Manning, M.L. (1997) 'The role of teacher collaboration in school reform', Childhood Education, 73(4), pp219-223.

Goddard, Y.L., Goddard, R.D., \&Tschannen-Moran, M. (2007) 'A theoretical and empirical investigation of teacher collaboration for school improvement and student achievement in public elementary schools', Teachers College Record, 109(4), pp877-896.

Hansen, D., Hill, D., McWalters, P., Paliokas, K., \&Stumbo, C. (2010) State Policy Implications of the Model Core Teaching Standards. Washington, D.C.:Council of Chief State School Officers

Hargreaves, A. (1994) Changing Teachers, Changing Times: Teachers' Work and Culture in the Postmodern Age. London: Cassell.

Hord, S. (1986) 'A synthesis of research on organizational collaboration', Educational Leadership, 43(5), pp22-26.

Johnson, B. (2003) 'Teacher collaboration: good for some, not so good for others', Educational Studies, 29(4), pp337-350.

Johnson, D.W. \& Johnson, F.P. (2000, $7^{\text {th }}$ Edition) Joining Together: Group Theory and Group Skills. Boston: Allyn \&Bacon.

John-Steiner, V. (2000) Creative Collaboration. New York: Oxford University Press.

Kelchtermans, G. (2006) 'Teacher collaboration and collegiality as workplace conditions: A review', ZeitschriftfürPädagogik, 52(2), pp 220-237.

Kelchtermans, G. (1996) 'Teacher vulnerability: understanding its moral and political roots', Cambridge Journal of Education, 26(3), pp307-323.

Kruse, S. (1999) 'Collaborate', Journal of Staff Development, 20(3), pp14-16.

Kruse, S.D., Louis, K.S., \&Bryk, A. (1995) 'An emerging framework for analyzing schoolbased professional community’ inLouis K.S. \& Kruse S.D. (Eds) Professionalism and Community: Perspectives on Reforming Urban Schools. Thousand Oaks, CA: Corwin, pp23-42.

Little, J.W. (1990) 'Teachers as colleagues' in Lieberman A. (Eds) Schools as Collaborative Cultures: Creating the Future Now. London: Falmer, pp170-198.

Lortie, D. (1975) School Teacher: A Sociological Study. Chicago: University of Chicago Press.

Louis, K.S. \& Kruse, S.D. (1995) Professionalism and Community: Perspectives on Reforming Urban Schools. Thousand Oaks, CA: Corwin.

McGregor, J. (2003) 'Making Spaces: Teacher workplace topologies', Pedagogy, Culture \& Society, 11(3),pp353-378.

Meirink, J.A., Meijer, P.C., \&Verloop, N. (2007). 'A closer look at teachers' individual learning in collaborative settings', Teachers and Teaching: Theory and Practice, 13(2), pp145-164.

Moolenaar, N.M., Sleegers, P.J.C. \& Daly A.J. (2012) 'Teaming up: Linking collaboration networks, collective efficacy, and student achievement', Teaching and Teacher Education, 28 (2), pp251-262. 
Nias, J., Southworth, G. \&Yeomans, R. (1989) Staff Relationships in the Primary School. London: Casswell.

O’Reilly, C.A.I. \& Roberts, K.H. (1977) 'Task group structure, communication, and effectiveness in three organizations', Journal of Applied Psychology, 62(6), pp. 674681.

Pianata, R.C. (1999) Enhancing Relationships between Children and Teachers. Washington, DC: American Psychological Association.

Roberts, S.M. \& Pruitt E.Z. (2003) Schools as Professional Learning Communities: Collaborative Activities and Strategies for Professional Development. Thousand Oaks, CA: Corwin.

Rozenholts, S. (1989) Teachers' Workplace: The Social Organization of Schools. New York: Longman.

Rust, F. (2009) 'Teacher research and the problem of practice', The Teachers College Record, 111(8), pp1882-1893.

Saunders, W.M., Goldenberg, C.N., \&Gallimore, R. (2009) 'Increasing achievement by focusing grade-level teams on improving classroom learning: a prospective, quasiexperimental study of Title I schools', American Educational Research Journal, 46(4), pp1006-1033.

Schlechty, P. (2005) Creating the capacity to support innovations. Louisville, Kentucky: Schlechty Center for Leadership in School Reform. Retrieved June 30, 2014. Available at: http://www.mikemcmahon.info/capacity.pdf(Last accessed 27 August 2014).

Silva, J.C. \&Morgado, J. (2005) 'Facilitators to collaboration between teachers: effects of gender, teaching experience and subject area', Inclusive and Supportive Education Congress International Special Education Conference Inclusion: Celebrating Diversity, 1st - 4th August 2005. Glasgow, Scotland. Available at: http://www.isec2005.org.uk/isec/abstracts/papers c/castrosilva_j.shtml (Last accessed 28 August 2014).

Smith, D., Wilson, B., \& Corbett, D. (2009) 'Moving beyond talk', Educational Leadership, 66(5), pp20-25.

Smylie, M.A. (1994) 'Redesigning teachers' work: Connections to the classroom', Review of Research in Education, 20(1), 129-177.

Stoll, L., Bolam, R., McMahon, A., Wallace, M., \& Thomas, S. (2006) 'Professional learning communities: A review of the literature', Journal of Educational Change, 7(4), pp221-258.

Strahan, D. (2003) 'Promoting a collaborative professional culture in three elementary schools that have beaten the odds', The Elementary School Journal, 104(2), pp127146.

Tschannen-Moran, M. (2001) 'Collaboration and the need for trust', Journal of Educational Administration, 39(4), pp308-331.

Watson, M. (2003) Learning to Trust: Transforming Difficult Elementary Classrooms through Developmental Discipline. San Francisco: Jossey-Bass.

Westheimer, J. (1999) 'Communities and consequences: an inquiry into ideology and practice in teachers' professional work', Educational Administration Quarterly, 35(1), pp71-105.

West, M.A. (1990) 'The social psychology of innovation in groups' in West, M.A.\& Farr J.L. (Eds.) Innovation and creativity at work: Psychological and organizational strategies. Chichester: Wiley, pp309-333). 
Woodland, R., Lee, M.K. \& Randall, J. (2013) 'A validation study of the teacher collaboration assessment survey, educational research and evaluation', An International Journal on Theory and Practice, 19(5), pp442-460.

\title{
Summary
}

\section{The Theoretical Framework of Teacher Collaboration}

\author{
Lyailya Shakenova \\ Queen's University Belfast, UK
}

In this study the focus will be on the existing literature about teacher collaboration.Firstly, the notion of collaboration in education and forms of collaborative culture will be outlined.Then the benefits and drawbacks of teacher collaboration will be discussed.The next step will outline the factors which restrict collaboration.Finally, factors which help to improve effective collaboration will be examined, which are divided into two main areas as structural conditions and interpersonal dynamics.

Keywords: Teacher collaboration, Factors affecting teacher collaboration, Benefits and drawbacks of teacher collaboration, Collaborative culture 